OPEN ACCESS

Edited by:

Colin T. Dourish,

P1 vital Limited, United Kingdom

Reviewed by:

Gavin P. Reynolds,

Sheffield Hallam University,

United Kingdom

Steven Vickers,

Syganture Discovery Ltd,

United Kingdom

*Correspondence:

Mong-Liang Lu

mongliang@hotmail.com

Specialty section:

This article was submitted to

Psychopharmacology,

a section of the journal

Frontiers in Psychiatry

Received: 11 September 2020 Accepted: 21 December 2020

Published: 20 January 2021

Citation:

Chen CY-A, Goh KK, Chen C-H and Lu M-L (2021) The Role of Adiponectin in the Pathogenesis of Metabolic Disturbances in Patients With Schizophrenia.

Front. Psychiatry 11:605124. doi: 10.3389/fpsyt.2020.605124

\section{The Role of Adiponectin in the Pathogenesis of Metabolic Disturbances in Patients With Schizophrenia}

\author{
Cynthia Yi-An Chen ${ }^{1}$, Kah Kheng Goh ${ }^{1,2}$, Chun-Hsin Chen ${ }^{1,2,3}$ and Mong-Liang Lu ${ }^{1,2,3 *}$ \\ ${ }^{1}$ Department of Psychiatry, Wan-Fang Hospital, Taipei Medical University, Taipei, Taiwan, ${ }^{2}$ Psychiatric Research Center, \\ Wan-Fang Hospital, Taipei Medical University, Taipei, Taiwan, ${ }^{3}$ Department of Psychiatry, School of Medicine, College of \\ Medicine, Taipei Medical University, Taipei, Taiwan
}

Antipsychotic-induced metabolic disturbance is a common adverse event occurring in patients treated with antipsychotic drugs. The mechanisms underlying metabolic dysregulation are complex, involving various neurochemical and hormonal systems, the interaction of genetic and lifestyle risk factors, and the antipsychotic drug prescribed. Recently, there has been increasing interest in the relationship between antipsychotic-induced metabolic disturbances and body weight regulatory hormones such as adiponectin. Adiponectin, an adipocyte-derived protein related to insulin sensitivity, weight gain, and anti-inflammation, has attracted great attention because of its potential role of being a biomarker to predict cardiovascular and metabolic diseases. Previous studies regarding the effects of antipsychotics on blood adiponectin levels have shown controversial results. Several factors might contribute to those inconsistent results, including different antipsychotic drugs, duration of antipsychotic exposure, age, sex, and ethnicity. Here we summarize the existing evidence on the link between blood adiponectin levels and metabolic disturbances related to antipsychotic drugs in patients with schizophrenia. We further discuss the effects of individual antipsychotics, patients' gender, ethnicity, age, and treatment duration on those relationships. We propose that olanzapine and clozapine might have a time-dependent biphasic effect on blood adiponectin levels in patients with schizophrenia.

Keywords: adiponectin, schizophrenia, antipsychotics, metabolic disturbance, leptin, ghrelin, time-dependent drug effect

\section{INTRODUCTION}

Schizophrenia is a major mental disease causing substantial impairment and burden (1). Patients with schizophrenia have higher rates of physical comorbidity and mortality compared to the general population $(2,3)$. In patients with schizophrenia, the risks of cardiovascular disease and metabolic disease are 2- and 5-fold higher, respectively, than in the general population $(4,5)$. People with schizophrenia have a 2-3 times increase in standard mortality ratio for all-cause mortality $(6,7)$. Metabolic and cardiovascular diseases play an important role in these tragedies (8). High mortality and morbidity in patients with schizophrenia may also be partially attributed to unhealthy behaviors, such as smoking, substance abuse, lack of exercise, and poor dietary habits 
(9). Data from drug-naïve populations suggested that people with schizophrenia may be susceptible to metabolic disturbances (10). However, these findings remain controversial $(11,12)$ and further investigations are needed to distinguish whether these findings are contributed to genetic factors or unhealthy lifestyle behaviors. Furthermore, antipsychotic drugs, especially some second-generation antipsychotics (SGAs) and low-potency first-generation antipsychotics (FGAs), also increase the risk of metabolic abnormalities (8).

The underlying mechanisms of antipsychotic-induced metabolic abnormalities are complex, involving various neurochemical and hormonal systems, the interaction of genetic and lifestyle risk factors, as well as the antipsychotic drug prescribed. The blockades of serotonin 5-hydroxytryptamine 2C $\left(5-\mathrm{HT}_{2} \mathrm{C}\right)$ and histamine $1\left(\mathrm{H}_{1}\right)$ receptors by antipsychotics have been associated with weight gain and metabolic dysregulations. Several studies found that adipokines, biologically active cytokines secreted by adipose tissue, may also play an important role (13). Among those adipokines, adiponectin plays a crucial role in causing the comorbid conditions of schizophrenia and metabolic dysregulation (Figure 1) (14). Previous reports have suggested differing results of the effects of antipsychotics on adiponectin levels. Several factors might contribute to these differing results, including different antipsychotic drugs, as well as patients' duration of antipsychotic exposure, age, sex, and ethnicity. In this review, we intend to summarize the role of adiponectin in patients comorbid with schizophrenia and metabolic disturbance. We also further discuss the effects of individual antipsychotics, gender, ethnicity, age, and treatment duration on adiponectin levels under those comorbid conditions.

\section{ANTIPSYCHOTIC DRUGS AND SIDE EFFECTS}

Antipsychotic drugs are the mainstay pharmacological treatment for patients with schizophrenia (15). Antipsychotic drugs are divided into FGAs and SGAs. FGAs work through dopamine $\mathrm{D}_{2}$ receptor blockade and are effective in treating positive symptoms of schizophrenia, such as hallucinations and delusion. Extrapyramidal symptoms (EPS) are common neurologic side effects of antipsychotic medications. The risk of EPS varies remarkably among individual antipsychotics. The efficacy of SGAs in improving positive and negative symptoms, cognition, as well as daily functioning has been proven (16-19). The antagonist action in both $5-\mathrm{HT}_{2}$ and $\mathrm{D}_{2}$ receptors are important for the therapeutic efficacy of SGAs. A recent network meta-analysis revealed that most antipsychotics have similar therapeutic efficacy but different side effect profiles (20). With few exceptions, only clozapine, amisulpride, zotepine, olanzapine, and risperidone are more effective in reducing overall symptoms of schizophrenia as compared with other antipsychotics (20). There are significant differences between antipsychotics concerning metabolic dysregulations, with olanzapine and clozapine exhibiting the worst profiles (21).

Metabolic adversities of antipsychotics have become a new challenge for clinicians (22). Several interconnected mechanisms of metabolic disturbance have been suggested, including increased appetite/food intake, physical inactivity and unhealthy lifestyle, as well as patients' characteristics such as gender and genetic variants (23). The binding of SGAs to $5-\mathrm{HT}_{2} \mathrm{C}$ and $\mathrm{H}_{1}$ receptors has also been associated with weight gain and metabolic alterations (24). Metabolic adversities can predict cardiovascular events, which are the main reason for higher mortality rates in patients with schizophrenia as compared to those in the general population $(6,25)$. Among commonly used antipsychotics, olanzapine, and clozapine are usually related to more metabolic side effects while aripiprazole, brexpiprazole, cariprazine, lurasidone, and ziprasidone establish better metabolic profiles (21). Lurasidone, cariprazine, aripiprazole, and brexpiprazole even show improved metabolic parameters in terms of glucose level, low-density lipoprotein (LDL) cholesterol level, and high-density lipoprotein (HDL) cholesterol level (21). Therefore, identifying metabolic abnormalities and early prevention of possible cardiovascular events in patients with schizophrenia become an important task. Several potential targets are proposed to be biomarkers of metabolic disturbances in patients with schizophrenia (2632). Among these, blood adiponectin level is a promising biomarker of cardiovascular and metabolic diseases, especially in antipsychotic-medicated patients $(28,33,34)$.

\section{THE ADIPONECTIN SIGNALING SYSTEM}

Adiponectin is secreted diurnally by adipocytes into the circulatory system, accounting for about $0.01-0.05 \%$ of total serum proteins (35), and functions as a messenger connecting adipose tissue and other organs (36). Human adiponectin comprises 244 amino acids and can be separated into three multimers: low molecular weight (LMW) form, trimer; middle molecular weight (MMW) form, hexamer; and high molecular weight (HMW) form, 12-18 monomers (37). After entering the circulating system, these multimers seldom interchange between different forms and present distinct biochemical characteristics (38). Previous studies support that adiponectin receptors are widely expressed in the brain $(39,40)$. Adiponectin can cross the blood-brain barrier and act directly on adiponectin receptors in the cortex, hypothalamus, and pituitary gland (39).

Adiponectin is an adipose-derived protein related to insulin sensitivity, weight gain, and anti-inflammation, attracting great attention recently because of its potential role of being a biomarker to predict metabolic syndrome $(41,42)$. Other than insulin-sensitizing and anti-inflammatory properties, adiponectin also shows anti-apoptotic, proangiogenic, antiatherogenic, proadipogenic $(37,43,44)$, and even anti-depressive effects $(45,46)$. In an animal study, treatment with adiponectin reduces blood levels of free fatty acid, triglycerides, and glucose (47). Higher blood adiponectin levels are associated with improvements in executive function and global cognition (48, 49), as well as lower risks of myocardial infarction, coronary artery disease, and other cardiovascular events (50). Failure to up-regulate adiponectin production may play an important role 


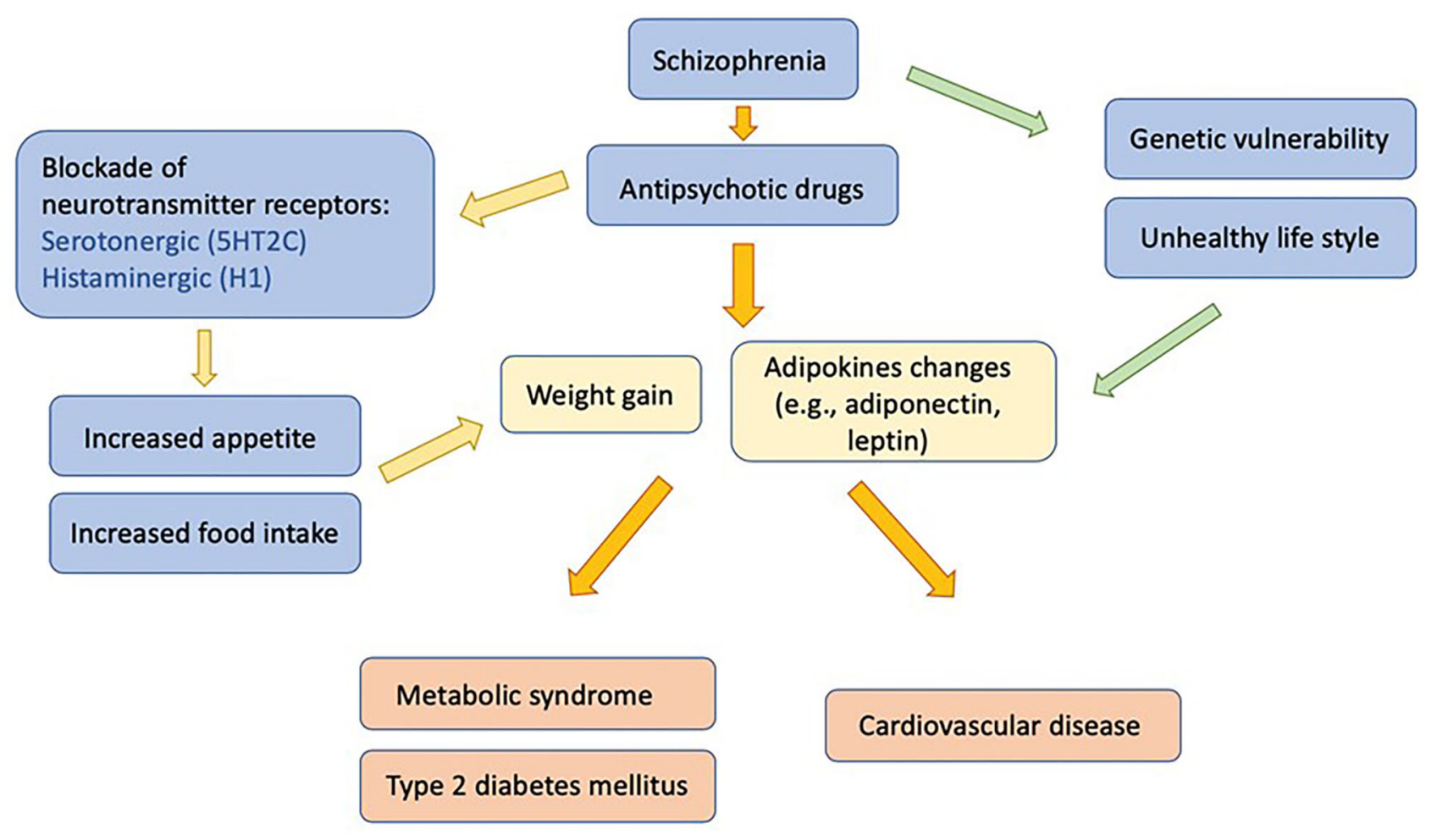

FIGURE 1 | Influences of antipsychotic medication on adipokines, metabolic disturbances, and associated morbidities in patients with schizophrenia.

in developing insulin resistance, diabetes mellitus, metabolic syndrome, and atherosclerosis (51).

Leptin, insulin-like growth factor, and growth hormone are positively related to adiponectin gene expression, while tumor necrosis factor- $\alpha$ (TNF- $\alpha$ ) and interleukin-6 (IL-6) act contrarily (37). However, the influence on adiponectin gene expression by insulin is differing, with some studies observing increased gene expression caused by insulin $(52,53)$ and some reporting down-regulation (54).

Antipsychotic drugs acting as antagonists at dopamine $\mathrm{D}_{2}$ receptors can stimulate prolactin release (55). Accumulating evidence suggests that prolactin may be linked to the development of type 2 diabetes mellitus through insulin signaling pathway (56). Furthermore, prolactin may act as an adipokine to suppress the production of adiponectin by adipocytes and influence energy homeostasis (57).

Two adiponectin receptors - adiponectin receptor 1 (AdipoR1) and adiponectin receptor 2 (AdipoR2) - prevalently express in the liver, muscle, heart, adipose tissue, pancreas, and the brain (58). Among multiple signaling molecules activated by adiponectin, adenosine monophosphate-activated protein kinase (AMPK) plays a major role in the downstream signaling (39). Adiponectin also works on AdipoR1, inducing extracellular calcium influx necessary for activating calcium/calmodulindependent protein kinase kinase (CaMKK) (58). Through binding to AdipoR2, adiponectin activates the expression of peroxisome proliferator-activated receptor alpha (PPAR $\alpha)$ ligands, as well as increases glucose and lipid metabolism
(51). Multiple studies have proven insulin-sensitizing effect of adiponectin, which mostly takes place in the liver and skeletal muscle (59-61). Adiponectin reduces triglyceride in the liver and muscle, but induces beta-oxidation in skeletal muscle via AMPK activation, leading to improvement in insulin sensitivity (37). Beside AMPK involvement, multiple signaling mechanisms through p38-mitogen-activated protein kinases (p38-MAPK), $\operatorname{PPAR} \alpha$, and adaptor protein, phosphotyrosine interacting with PH domain and leucine zipper 1 (APPL1) are reported (39). Several studies proposed that impaired adiponectin action is a hallmark of obesity-linked diseases, through the mechanism of hypoadiponectinemia and down-regulation of adiponectin receptors (58).

Previous evidence suggested that peripheral effects of adiponectin are mainly mediated by HMW adiponectin (39). But increasing studies proposed that LMW adiponectin might be the active forms in the central nervous system, as LMW adiponectin has been detected in human cerebrospinal fluid $(62,63)$. Further studies are necessary to explore the role of adiponectin in the brain and the effects of different adiponectin multimers.

\section{High Molecular Weight Adiponectin}

Although blood LMW adiponectin, MMW adiponectin, and HMW adiponectin levels are all lower in patients with metabolic syndrome, HMW adiponectin is a stronger candidate to predict insulin resistance and metabolic syndrome among different multimers of adiponectin (64). Studies have shown decreased blood HMW adiponectin level resulting in the progression of 


\section{Effects of SGAs on Adiponectin levels}

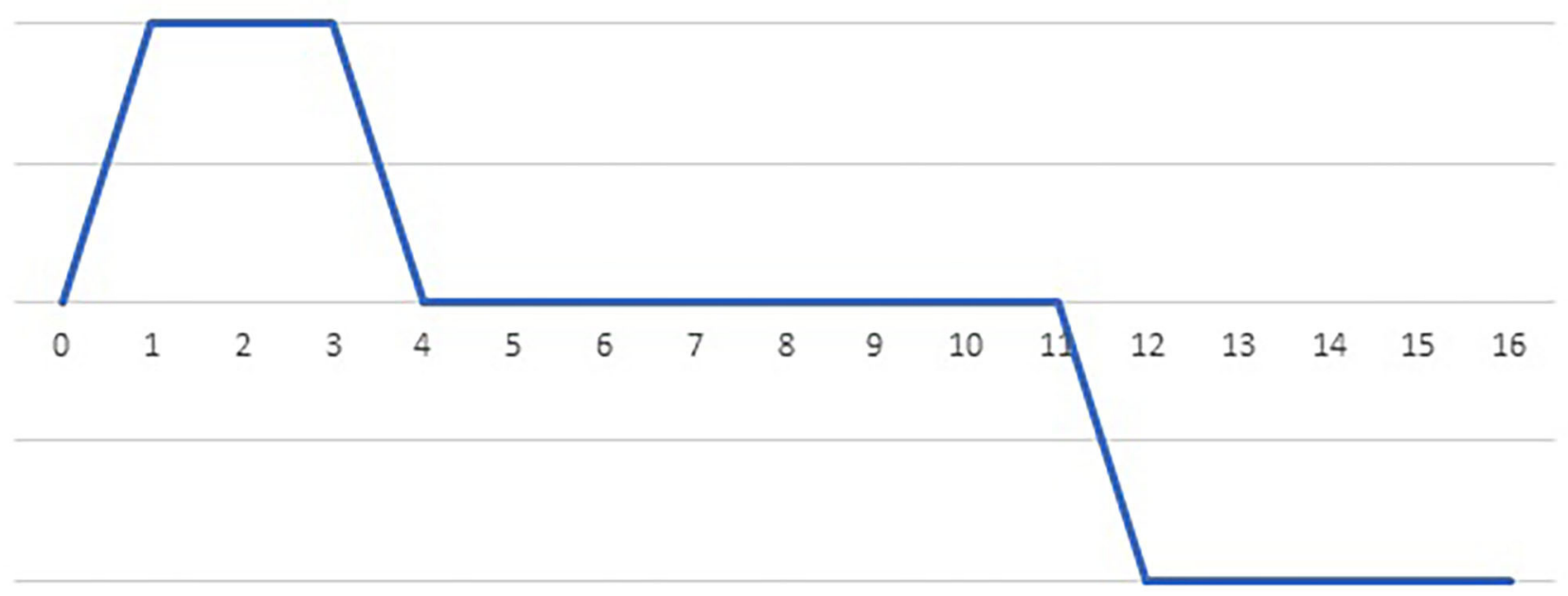

FIGURE 2 | The bi-phasic effects of olanzapine and clozapine on blood adiponectin levels over time. A single dose of olanzapine or clozapine had no influence on blood adiponectin levels. Treatment with olanzapine or clozapine up-regulates blood adiponectin levels acutely ( $t=1-4$ weeks), to compensate for the side effect on glucose homeostasis. Then, a new energy balance equilibrium is re-established during short-term treatment (4-12 weeks), returning blood adiponectin levels to the baseline. Finally, the failure of adiponectin up-regulation pushes blood adiponectin levels further below the baseline after long-term treatment (more than 3 months).

metabolic syndrome and even type 2 diabetes mellitus (6567). Blood HMW adiponectin level is proposed to be a better predictor of the progression to metabolic syndrome compared to total blood adiponectin level or HMW/total adiponectin ratio $(67,68)$. HMW adiponectin has the strongest relationship with insulin sensitivity as compared with LMW adiponectin or HMW/total adiponectin ratio (68). Chen et al. also reported that only HMW adiponectin level is correlated with insulin sensitivity rather than total adiponectin level in patients with schizophrenia (26).

A study by Lee et al. has reported lower HMW adiponectin levels in patients with schizophrenia compared to non-psychiatric controls (33). Both schizophrenia and nonpsychiatric groups have shown that lower HMW adiponectin levels are associated with higher body mass index, worse risk for coronary heart disease, higher number of metabolic syndrome criteria, greater insulin resistance, lower levels of HDL cholesterol, and higher levels of high sensitivity C-reactive protein (CRP) (33).

\section{Leptin and Leptin/Adiponectin Ratio}

Leptin is also an adipose-derived protein related to appetite, obesity, energy balance, insulin resistance, and other metabolic parameters. Elevated blood leptin level is associated with insulin resistance and the risk of metabolic syndrome. Hyperleptinemia can also be a risk factor for cardiovascular disease $(64,69)$. Elevated blood leptin levels are observed in patients with schizophrenia, particularly in those taking SGAs (70). Leptin might be one of the factors involving in the mechanisms of SGAs related to body weight gain and adiposity (71). Although both adiponectin and leptin levels have the potential to be biomarkers for predicting metabolic syndrome (41, 72-74), recent studies have suggested leptin/adiponectin ratio (L/A ratio) as a stronger candidate as compared with adiponectin and leptin alone (27, 73). The L/A ratio is positively correlated with most of the metabolic parameters, including body weight, body mass index, waist circumference, cholesterol level, triglycerides level, LDL level, insulin level (27), and most prominently, insulin resistance $(27,75,76)$. In addition, the L/A ratio is positively correlated to the blood levels of CRP and amyloid A (SAA), which are obesityrelated inflammatory markers (77). This finding implies that the $\mathrm{L} / \mathrm{A}$ ratio can be a biomarker to predict the severity of adipose tissue dysfunction and cardiometabolic risk (78).

Regarding as a biomarker of metabolic abnormality, the cutoff point of the L/A ratio is still inconclusive. Frühbeck et al. have proposed to define the L/A ratio value below 1 as normal, between 1 and 2 as moderate, above 2 as severe cardiometabolic risk in the general population (78). Another study by Larsen et al. suggested 
that the cut-off value at 1.88 can detect increased risks of early obesity-related metabolic disturbances (79). A study by Chen et al. reported that the L/A ratio can better discriminate against schizophrenia patients with and without metabolic syndrome than using the value of either leptin or adiponectin (27). They have proposed 0.61 as the optimal cut-off value of the L/A ratio for metabolic syndrome in patients with schizophrenia (27).

\section{Ghrelin}

Ghrelin, a 28-amino-acid orexigenic peptide, is predominantly produced by the stomach (80). In humans, ghrelin stimulates growth hormone release, modifies energy homeostasis, increases appetite, and leads to weight gain (81). In addition, an increase in blood ghrelin levels dysregulates adipose-liver interaction, increases the free fatty acid released from adipose tissue, as well as alters adiponectin and cytokine secretion (82). The action of ghrelin contributes to the development of the metabolic syndrome and type 2 diabetes mellitus (83). Zhang et al. proposed that SGAs have a time-dependent effect on serum ghrelin levels, with an initial increase by the acute effect of SGAs in the first week, followed by a down-regulation due to negative feedback from SGA-induced weight gain in 2-6 weeks, and finally a return to baseline or above during long-term SGA treatment (84). But the effect of antipsychotics on ghrelin level varies depending on individual antipsychotics, patients' age, gender, dietary pattern, lifestyle, physical and psychiatric co-morbidity, co-medication, as well as other confounding factors $(84,85)$. In addition, acylated ghrelin and desacylated ghrelin are the two main forms of serum ghrelin, demonstrating different roles in energy homeostasis (83). A study by $\mathrm{Wu}$ et al. revealed that acylated/desacylated ghrelin ratio is a better biomarker for metabolic syndrome than other ghrelin parameters in olanzapine-treated patients with schizophrenia (30).

\section{EFFECTS OF ANTIPSYCHOTICS ON ADIPONECTIN}

\section{Drug-Naïve Patients With Schizophrenia}

Metabolic adversities are well-known adverse effects of antipsychotic drugs. It is still debatable whether metabolic syndrome in patients with schizophrenia is induced by antipsychotics or schizophrenia per se. Available evidence suggests that the clinical efficacy and side effects of antipsychotics vary from patient to patient. The large individual variability of metabolic abnormality of antipsychotics can be attributed to multifactorial mechanisms, in which genetic factors may be essential. A twin study has highlighted the possibility of genetic factors for weight gain after antipsychotic treatment (86). Several genes have been reported to be strongly associated with metabolic syndrome in patients with schizophrenia, such as the fat mass and obesity-associated gene (FTO), leptin and leptin receptor genes (LEP, LEPR), methylenetetrahydrofolate reductase (MTHFR) gene, catechol-o-methyl transferase (COMT) gene, insulin-induced gene (INSIG) 2, sterol regulatory element-binding transcription factor 2 (SREBF2) gene, dopamine receptor $\mathrm{D} 2$ gene (DRD2), and the serotonin receptor $2 \mathrm{C}$ gene (HTR2C) (87-90).
Some studies showed that even drug-naïve patients with schizophrenia are more vulnerable to metabolic adversities than healthy controls, with the manifestation of glucose intolerance and insulin resistance before antipsychotic use (91-94). Increased visceral fat deposition has also been discovered in drug-naïve schizophrenia patients (95). On the other hand, a meta-analysis by Bartoli et al. revealed that blood adiponectin levels in drugnaïve patients with schizophrenia are not different from those of healthy controls (96). These findings suggest that metabolic disturbances of drug-naïve schizophrenia patients are caused by a mechanism other than the adiponectin pathway.

\section{Individual Antipsychotics}

Antipsychotic drugs are widely used in several mental illness entities and give a different extent of risk for antipsychoticinduced metabolic dysregulation. Almost all antipsychotic drugs, including FGAs and SGAs, cause metabolic side effects with quantitative and qualitative differences (97). Recently published data have ranked clozapine and olanzapine as having the highest risk of metabolic adversity, followed by paliperidone, quetiapine, risperidone, and haloperidol in the middle, and aripiprazole, lurasidone, and ziprasidone with the lowest risk (14,98). A recent meta-analysis reported that schizophrenia per se is not associated with lower blood adiponectin levels (96). Schizophrenia patients with metabolic syndrome have lower blood adiponectin levels as compared to those without metabolic syndrome, and blood adiponectin levels are decreased as the number of metabolic syndrome components is increased $(99,100)$. Individuals with schizophrenia taking SGAs have lower blood adiponectin levels than normal controls (96). Furthermore, differential effects exist on blood adiponectin levels among various antipsychotic drugs.

\section{Haloperidol}

Haloperidol has the least potential to cause weight gain among antipsychotic drugs (21). Pre-clinical and clinical studies proposed that haloperidol seemed not to affect blood adiponectin level. In vitro study found that haloperidol does not cause adiponectin (ADIPOQ) gene expression (101). In vivo study revealed that 12-week haloperidol medication in Sprague Dawley rats shows lower weight gain and similar blood adiponectin levels compared to controls (102). A study by Perez-Iglesias et al. found that body weights increase and blood adiponectin levels remain unchanged in drug-naive psychotic patients after a 1-year haloperidol treatment (103). Raposo et al. also reported that body weights and blood adiponectin levels are similar in patients with schizophrenia after a 9-month haloperidol medication (104).

\section{Risperidone}

Risperidone shows a moderate risk of metabolic dysregulation among antipsychotics (21). In vitro study reported that risperidone increases the expression of ADIPOQ gene (105). An in vivo study revealed that risperidone increases adiponectin mRNA in male Sprague-Dawley rats (106). A study by PerezIglesias et al. showed that blood adiponectin levels increase after a one-year risperidone treatment in drug-naive psychotic patients (103). Wampers et al., and Sugai et al. also found that blood adiponectin levels increase in schizophrenia patients receiving 
risperidone treatment for 3 and 12 months, respectively (107, 108).

\section{Olanzapine}

Olanzapine exhibits the highest risk of metabolic dysregulation among antipsychotics (21). An in vitro study reported that 7-day olanzapine exposure does not affect total adiponectin expression or multimer composition of secreted protein (109). Another in vitro study found that an 11-day olanzapine exposure has moderate effects on ADIPOQ gene expression (101). In an animal study using female rats, olanzapine-induced hyperphagia has been found to cause weight gain, increased adiposity, and subsequent insulin resistance, although the latter may be alleviated by the compensatory response to produce adiponectin (110). Astudy by Cooper et al. revealed that male olanzapinemedicated rats have neither hyperphagia, reduced weight gain, enhanced visceral adiposity, nor increased blood adiponectin level (111), whereas another study has shown an increased body weight and subcutaneous fat deposition in male rats receiving higher doses of olanzapine (112). This trend of sex difference has been found in many animal studies receiving different antipsychotics (113-115).

In human studies, a single dose of $10 \mathrm{mg}$ olanzapine does not cause any effect on blood adiponectin levels in healthy controls (116). Increased blood levels of triglyceride and adiponectin have been found after an 8-day olanzapine use in non-psychotic healthy male subjects (117). After receiving a 4-week treatment of olanzapine, patients with schizophrenia have remarkable weight gains but no changes in blood adiponectin levels (118). Schizophrenia patients under olanzapine for more than 3 months have decreased blood adiponectin levels $(70,107)$. Base on those findings we suggest that olanzapine might have a time-dependent effect on blood adiponectin levels in patients with schizophrenia.

\section{Clozapine}

An in vitro study revealed that clozapine can induce the expression of ADIPOQ gene $(101,105)$. An animal study by von Wilmsdorff et al. has shown weight gain and increased blood adiponectin levels in male rats receiving clozapine, as compared with controls (102).

In a human study, a 6-week administration of clozapine has shown no changes in blood adiponectin levels among patients with childhood-onset schizophrenia (119). Patients with schizophrenia receiving long-term clozapine medication have lower blood adiponectin levels than healthy subjects (70). In patients with schizophrenia receiving clozapine for at least 3 months, blood adiponectin levels are negatively associated with weight gain and metabolic parameters after receiving clozapine treatment (28). Being independent of age and body mass index, hypoadiponectinemia is a potential biomarker of the metabolic syndrome in schizophrenia patients receiving clozapine treatment (28). Similar to olanzapine, clozapine has a time-dependent effect on blood adiponectin levels in patients with schizophrenia.

\section{Aripiprazole}

The results of the effect of aripiprazole on adiponectin are inconsistent. An in-vitro study reported that aripiprazole increases blood adiponectin levels in the supernatants on mouse fibroblast cultures (120). Another in-vitro study revealed that aripiprazole does not change the mRNA expression of ADIPOQ gene on human subcutaneous adipose tissue (121). The study by Gao et al. reported that patients with first episode schizophrenia receiving a 24-week aripiprazole treatment have lower blood adiponectin levels than those before treatment (122). The study by Wang et al. reported that after aripiprazole augmentation for 8 weeks, patients treated with olanzapine have decreased body weight and blood triglyceride levels, but increased adiponectin blood levels (123). Further studies are warranted to investigate the effect of aripiprazole on adiponectin production.

\section{GENDER, ETHNIC, AND AGE EFFECTS ON ADIPONECTIN LEVELS}

In the majority of clinical studies, female patients receiving antipsychotics tend to gain more weight and be diagnosed with metabolic syndrome when compared to male counterparts (124). The vulnerability of female rodents to weight gain and metabolic side effects of SGAs over male ones is comparable to that found in the clinical studies $(110,111)$. Gender difference in blood adiponectin levels has also been found. In both animal and human studies, females show higher total and HMW adiponectin levels than males $(27,125-127)$, which may be contributed to the effect of androgens (126). Since androgens are likely to play an inhibitory role in blood adiponectin level, women are then expected to have higher blood adiponectin levels than men. This trend has also been found in patients with schizophrenia, with male patients presenting lower blood adiponectin level and lower L/A ratio comparing to female patients (27), although not all studies replicated the same results (96). Moreover, Chen et al. revealed that L/A ratio has a stronger predictive ability for metabolic syndrome in male patients than in female counterparts (27). Matsuda et al. reported an association of obesity and decreased plasma adiponectin level only observed in male patients with schizophrenia but not in female patients (128). The correlation of obesity and elevated insulin resistance is also more prominent in the male group than the female one (128).

Ethnic and intra-ethnic variations exist, with higher blood adiponectin levels in Europeans and Aboriginal people as compared with Chinese and South Asians (129). Both South Asians and Aboriginal people show increased insulin resistance when blood adiponectin levels are decreased (129). Another study reported that the impact of body mass index on insulin resistance, CRP, and adiponectin appears greater in Chinese as compared with other major Asian ethnic groups (130). The study by Lee et al. reported that lower blood levels of HMW adiponectin are associated with minority race/ethnicity in patients with schizophrenia (33).

Remarkably, the effect of adiponectin varies in different age groups. Studies in people without schizophrenia have reported higher blood adiponectin levels with aging, proposing that higher 
blood adiponectin levels in older adults do not reflect better health as they do in younger persons (131). In a healthy middleaged population (aged 40-59 years), low blood adiponectin levels are associated with a higher risk of coronary heart disease (50). But in people aged 65 and older, higher blood adiponectin levels are found to be associated with an increased risk of coronary heart disease $(132,133)$. Cohort studies revealed that blood adiponectin levels increase over time in older people and are associated with greater physical disability and mortality (131).

\section{TIME-DEPENDENT EFFECT OF ANTIPSYCHOTICS ON ADIPONECTIN LEVELS}

In addition to the individual characteristics of antipsychotic drugs, the duration of antipsychotic medication might also contribute to the inconsistent results of the effect of antipsychotics on blood adiponectin levels (Figure 2). A single dose of $10 \mathrm{mg}$ olanzapine has no effect on blood adiponectin levels in healthy controls (116). After an 8-day olanzapine treatment in healthy males, blood triglyceride levels, insulin resistance, and adiponectin levels increased (117). This upregulation of adiponectin might compensate for the detrimental effect of olanzapine on insulin sensitivity. After a 4-week olanzapine medication, patients with schizophrenia show weight gains but no changes in blood adiponectin levels (118). Schizophrenia patients receiving olanzapine for more than 3 months have decreased blood adiponectin levels $(70,107)$. Clozapine also has similar time-dependent effects on blood adiponectin levels. After receiving 6-week clozapine medication, patients with childhood-onset schizophrenia show no changes in blood adiponectin levels (119). After receiving clozapine treatment for more than 3 months, patients with schizophrenia have increased body weight and decreased blood adiponectin levels $(28,70)$. Srisawasdi et al. also proposed that risperidone treatment decreases blood adiponectin levels in a durationdependent manner in children and adolescents with autistic spectrum disorders (134).

Apparently, the effect of olanzapine and clozapine on blood adiponectin levels might vary according to the duration of treatment (Figure 2). We propose that olanzapine and clozapine might have a time-dependent biphasic effect on adiponectin levels in patients with schizophrenia. Initially, the up-regulation of adiponectin might compensate for the deleterious effect of olanzapine and clozapine on glucose homeostasis. Then a new energy balance equilibrium is re-established during a short-term treatment, resulting in the return of blood adiponectin levels to the baseline. Finally, the failure of adiponectin up-regulation

\section{REFERENCES}

1. Charlson FJ, Ferrari AJ, Santomauro DF, Diminic S, Stockings E, Scott JG, et al. Global epidemiology and burden of schizophrenia: findings from the Global Burden of Disease Study 2016. Schizophr Bull. (2018) 44:1195203. doi: $10.1093 /$ schbul/sby058 pushes blood adiponectin levels further below the baseline after long-term treatment.

\section{CONCLUSION}

Metabolic disturbance is a common side effect of antipsychotic treatment. The mechanisms underlying metabolic dysregulation are complex, involving various neurochemical and hormonal systems, the interaction of genetic and lifestyle risk factors, as well as the antipsychotic drug prescribed. Clinical and preclinical data indicated that failure to upregulate adiponectin production is related to antipsychotic-induced metabolic disturbances. But differential effects on blood adiponectin levels exist among various antipsychotic drugs. Additionally, treatment duration, sex, age, and ethnicity also influence blood levels of adiponectin and the risk of metabolic syndrome. We suggest that olanzapine and clozapine might have a time-dependent biphasic effect on adiponectin levels in patients with schizophrenia. To elucidate the role of adiponectin in antipsychotic-induced metabolic dysregulations, future studies are warranted to investigate the impacts of those factors on energy homeostasis.

In conclusion, recognition of regulatory effects of adiponectin under antipsychotic medication could lead to novel treatment approaches for metabolic disturbances of patients with schizophrenia. As the new era of personalized medications has arrived, potential markers that provide information on possible metabolic risk can help clinicians adjust therapeutic strategy to prevent suffering owing to metabolic dysfunction or even associated premature death. Furthermore, up-regulation of the adiponectin receptor pathway might be a potential therapeutic target for antipsychotic-induced metabolic disturbances.

\section{AUTHOR CONTRIBUTIONS}

M-LL provided the ideation and writing of the manuscript. CY-AC contributed significantly to the writing of the manuscript. KKG reviewed the literature papers that were used for writing the manuscript. C-HC has made a critical review of the manuscript. All authors contributed to the article and approved the submitted version.

\section{FUNDING}

This work was financially supported by the Higher Education Sprout Project of the Ministry of Education (MOE) (DP2-10921121-01-N-07-04) and Ministry of Science and Technology (MOST 109-2314-B-038-083 and MOST 108-2314-B-038-076) in Taiwan. 
4. Azad MC, Shoesmith WD, Al Mamun M, Abdullah AF, Naing DK, Phanindranath $M$, et al. Cardiovascular diseases among patients with schizophrenia. Asian J Psychiatry. (2016) 19:28-36. doi: 10.1016/j.ajp.2015.11.012

5. Mitchell AJ, Vancampfort D, Sweers K, van Winkel R, Yu W, De Hert M. Prevalence of metabolic syndrome and metabolic abnormalities in schizophrenia and related disorders-a systematic review and meta-analysis. Schizophr Bull. (2013) 39:306-18. doi: 10.1093/schbul/sbr148

6. Saha S, Chant D, McGrath J. A systematic review of mortality in schizophrenia: is the differential mortality gap worsening over time? Arch Gen Psychiatry. (2007) 64:1123-31. doi: 10.1001/archpsyc.64.10.1123

7. Oakley P, Kisely S, Baxter A, Harris M, Desoe J, Dziouba A, et al. Increased mortality among people with schizophrenia and other non-affective psychotic disorders in the community: a systematic review and meta-analysis. J Psychiatric Res. (2018) 102:245-53. doi: 10.1016/j.jpsychires.2018.04.019

8. Ventriglio A, Gentile A, Stella E, Bellomo A. Metabolic issues in patients affected by schizophrenia: clinical characteristics and medical management. Front Neurosci. (2015) 9:297. doi: 10.3389/fnins.2015.00297

9. De Hert M, Schreurs V, Vancampfort D, Van Winkel R. Metabolic syndrome in people with schizophrenia: a review. World Psychiatry. (2009) 8:1522. doi: 10.1002/j.2051-5545.2009.tb00199.x

10. Enez Darcin A, Yalcin Cavus S, Dilbaz N, Kaya H, Dogan E. Metabolic syndrome in drug-naive and drug-free patients with schizophrenia and in their siblings. Schizophrenia Res. (2015) 166:201-6. doi: 10.1016/j.schres.2015.05.004

11. Misiak B, Wisniewski M, Lis M, Samochowiec J, Stanczykiewicz B. Glucose homeostasis in unaffected first-degree relatives of schizophrenia patients: a systematic review and meta-analysis. Schizophrenia Res. (2020) 223:28. doi: 10.1016/j.schres.2020.07.011

12. Mitchell AJ, Vancampfort D, De Herdt A, Yu W, De Hert M. Is the prevalence of metabolic syndrome and metabolic abnormalities increased in early schizophrenia? A comparative meta-analysis of first episode, untreated and treated patients. Schizophr Bull. (2013) 39:295305. doi: 10.1093/schbul/sbs082

13. Wedrychowicz A, Zajac A, Pilecki M, Koscielniak B, Tomasik PJ. Peptides from adipose tissue in mental disorders. World J Psychiatry. (2014) 4:10311. doi: $10.5498 /$ wjp.v4.i4.103

14. Bartoli F, Crocamo C, Clerici M, Carra G. Second-generation antipsychotics and adiponectin levels in schizophrenia: a comparative meta-analysis. Eur Neuropsychopharmacol. (2015) 25:1767-74. doi: 10.1016/j.euroneuro.2015.06.011

15. Lehman AF, Lieberman JA, Dixon LB, McGlashan TH, Miller AL, Perkins DO, et al. Practice guideline for the treatment of patients with schizophrenia, second edition. Am J Psychiatry. (2004) 161(2 Suppl.):1-56.

16. Glick ID, Suppes T, DeBattista C, Hu RJ, Marder S. Psychopharmacologic treatment strategies for depression, bipolar disorder, and schizophrenia. Ann Intern Med. (2001) 134:47-60. doi: 10.7326/0003-4819-134-1-200101020-00013

17. Miyamoto S, Miyake N, Jarskog LF, Fleischhacker WW, Lieberman JA. Pharmacological treatment of schizophrenia: a critical review of the pharmacology and clinical effects of current and future therapeutic agents. Mol Psychiatry. (2012) 17:1206-27. doi: 10.1038/mp.2012.47

18. Barnes TR, Drake R, Paton C, Cooper SJ, Deakin B, Ferrier IN, et al. Evidence-based guidelines for the pharmacological treatment of schizophrenia: updated recommendations from the British Association for Psychopharmacology. J Psychopharmacol. (2020) 34:3-78. doi: 10.1177/0269881119889296

19. Newcomer JW. Second-generation (atypical) antipsychotics and metabolic effects: a comprehensive literature review. CNS Drugs. (2005) 19(Suppl. 1):1-93. doi: 10.2165/00023210-200519001-00001

20. Huhn M, Nikolakopoulou A, Schneider-Thoma J, Krause M, Samara M, Peter N, et al. Comparative efficacy and tolerability of 32 oral antipsychotics for the acute treatment of adults with multi-episode schizophrenia: a systematic review and network meta-analysis. Lancet. (2019) 394:93951. doi: 10.1016/S0140-6736(19)31135-3

21. Pillinger T, McCutcheon RA, Vano L, Mizuno Y, Arumuham A, Hindley G, et al. Comparative effects of 18 antipsychotics on metabolic function in patients with schizophrenia, predictors of metabolic dysregulation, and association with psychopathology: a systematic review and network meta-analysis. Lancet Psychiatry. (2020) 7:64-77. doi: 10.1016/S2215-0366(19)30416-X

22. Leucht S, Corves C, Arbter D, Engel RR, Li C, Davis JM. Second-generation versus first-generation antipsychotic drugs for schizophrenia: a metaanalysis. Lancet. (2009) 373:31-41. doi: 10.1016/S0140-6736(08)61764-X

23. Spertus J, Horvitz-Lennon M, Abing H, Normand SL. Risk of weight gain for specific antipsychotic drugs: a meta-analysis. NPJ Schizophrenia. (2018) 4:12. doi: 10.1038/s41537-018-0053-9

24. Grajales D, Ferreira V, Valverde AM. Second-generation antipsychotics and dysregulation of glucose metabolism: beyond weight gain. Cells. (2019) 8:1336. doi: $10.3390 /$ cells 8111336

25. Jeon SW, Kim YK. Unresolved issues for utilization of atypical antipsychotics in schizophrenia: antipsychotic polypharmacy and metabolic syndrome. Int J Mol Sci. (2017) 18:2174. doi: 10.3390/ijms18102174

26. Chen PY, Huang MC, Chiu CC, Liu HC, Lu ML, Chen CH. Association of plasma retinol-binding protein-4, adiponectin, and high molecular weight adiponectin with metabolic adversities in patients with schizophrenia. Prog Neuropsychopharmacol Biol Psychiatry. (2011) 35:1927-32. doi: 10.1016/j.pnpbp.2011.07.014

27. Chen VC, Chen CH, Chiu YH, Lin TY, Li FC, Lu ML. Leptin/Adiponectin ratio as a potential biomarker for metabolic syndrome in patients with schizophrenia. Psychoneuroendocrinology. (2018) 92:34-40. doi: 10.1016/j.psyneuen.2018.03.021

28. Bai YM, Chen JY, Yang WS, Chi YC, Liou YJ, Lin CC, et al. Adiponectin as a potential biomarker for the metabolic syndrome in Chinese patients taking clozapine for schizophrenia. J Clin Psychiatry. (2007) 68:18349. doi: 10.4088/JCP.v68n1202

29. Beumer W, Drexhage RC, De Wit H, Versnel MA, Drexhage HA, Cohen D. Increased level of serum cytokines, chemokines and adipokines in patients with schizophrenia is associated with disease and metabolic syndrome. Psychoneuroendocrinology. (2012) 37:1901-11. doi: 10.1016/j.psyneuen.2012.04.001

30. Wu TH, Chiu CC, Goh KK, Chen PY, Huang MC, Chen $\mathrm{CH}$, et al. Relationship between metabolic syndrome and acylated/desacylated ghrelin ratio in patients with schizophrenia under olanzapine medication. $J$ Psychopharmacol. (2020) 34:86-92. doi: 10.1177/0269881119885260

31. Chen PY, Chen CH, Chang CK, Kao CF, Lu ML, Lin SK, et al. OrexinA levels in relation to the risk of metabolic syndrome in patients with schizophrenia taking antipsychotics. Int J Neuropsychopharmacol. (2019) 22:28-36. doi: 10.1093/ijnp/pyy075

32. $\mathrm{Lu}$ ML, Chen $\mathrm{CH}$, Kuo PT, Lin CH, Wu TH. Application of plasma levels of olanzapine and $\mathrm{N}$-desmethyl-olanzapine to monitor metabolic parameters in patients with schizophrenia. Schizophrenia Res. (2018) 193:139-45. doi: 10.1016/j.schres.2017.07.022

33. Lee EE, Sears DD, Liu J, Jin H, Tu XM, Eyler LT, et al. A novel biomarker of cardiometabolic pathology in schizophrenia? J Psychiatric Res. (2019) 117:31-7. doi: 10.1016/j.jpsychires.2019.06.011

34. Achari AE, Jain SK. Adiponectin, a therapeutic target for obesity, diabetes, and endothelial dysfunction. Int J Mol Sci. (2017) 18:1321. doi: 10.3390/ijms18061321

35. Pajvani UB, Du X, Combs TP, Berg AH, Rajala MW, Schulthess $\mathrm{T}$, et al. Structure-function studies of the adipocyte-secreted hormone Acrp30/adiponectin. Implications fpr metabolic regulation and bioactivity. J Biol Chem. (2003) 278:9073-85. doi: 10.1074/jbc.M207198200

36. Wang ZV, Scherer PE. Adiponectin, the past two decades. J Mol Cell Biol. (2016) 8:93-100. doi: 10.1093/jmcb/mjw011

37. Fang H, Judd RL. Adiponectin regulation and function. Compr Physiol. (2018) 8:1031-63. doi: 10.1002/cphy.c170046

38. Schraw T, Wang ZV, Halberg N, Hawkins M, Scherer PE. Plasma adiponectin complexes have distinct biochemical characteristics. Endocrinology. (2008) 149:2270-82. doi: 10.1210/en.2007-1561

39. Thundyil J, Pavlovski D, Sobey CG, Arumugam TV. Adiponectin receptor signalling in the brain. Br J Pharmacol. (2012) 165:31327. doi: 10.1111/j.1476-5381.2011.01560.x

40. Qi Y, Takahashi N, Hileman SM, Patel HR, Berg AH, Pajvani UB, et al. Adiponectin acts in the brain to decrease body weight. Nat Med. (2004) 10:524-9. doi: 10.1038/nm1029 
41. Matsuzawa Y, Funahashi T, Kihara S, Shimomura I. Adiponectin and metabolic syndrome. Arterioscler Thromb Vasc Biol. (2004) 24:2933. doi: 10.1161/01.ATV.0000099786.99623.EF

42. Orlando A, Nava E, Giussani M, Genovesi S. Adiponectin and cardiovascular risk. From pathophysiology to clinic: focus on children and adolescents. Int J Mol Sci. (2019) 20:3228. doi: 10.3390/ijms20133228

43. Choi HM, Doss HM, Kim KS. Multifaceted physiological roles of adiponectin in inflammation and diseases. Int J Mol Sci. (2020) 21:1219. doi: 10.3390/ijms21041219

44. Abou-Samra M, Selvais CM, Dubuisson N, Brichard SM. Adiponectin and its mimics on skeletal muscle: insulin sensitizers, fat burners, exercise mimickers, muscling pills... or everything together? Int J Mol Sci. (2020) 21:2620. doi: 10.3390/ijms21072620

45. Diniz BS, Teixeira AL, Campos AC, Miranda AS, Rocha NP, Talib LL, et al. Reduced serum levels of adiponectin in elderly patients with major depression. J Psychiatric Res. (2012) 46:1081-5. doi: 10.1016/j.jpsychires.2012.04.028

46. Liu J, Guo M, Zhang D, Cheng SY, Liu ML, Ding J, et al. Adiponectin is critical in determining susceptibility to depressive behaviors and has antidepressant-like activity. Proc Natl Acad Sci USA. (2012) 109:1224853. doi: $10.1073 /$ pnas. 1202835109

47. Fruebis J, Tsao TS, Javorschi S, Ebbets-Reed D, Erickson MR, Yen FT, et al. Proteolytic cleavage product of $30-\mathrm{kDa}$ adipocyte complement-related protein increases fatty acid oxidation in muscle and causes weight loss in mice. Proc Natl Acad Sci USA. (2001) 98:2005-10. doi: 10.1073/pnas.98.4.2005

48. Wennberg AM, Gustafson D, Hagen CE, Roberts RO, Knopman D, Jack C, et al. Serum adiponectin levels, neuroimaging, and cognition in the mayo clinic study of aging. J Alzheimers Dis. (2016) 53:573-81. doi: 10.3233/JAD-151201

49. Rizzo MR, Fasano R, Paolisso G. Adiponectin and cognitive decline. Int J Mol Sci. (2020) 21:2010. doi: 10.3390/ijms21062010

50. Sattar N, Wannamethee G, Sarwar N, Tchernova J, Cherry L, Wallace AM, et al. Adiponectin and coronary heart disease: a prospective study and meta-analysis. Circulation. (2006) 114:623-9. doi: 10.1161/CIRCULATIONAHA.106.618918

51. Yamauchi T, Kadowaki T. Adiponectin receptor as a key player in healthy longevity and obesity-related diseases. Cell Metab. (2013) 17:18596. doi: 10.1016/j.cmet.2013.01.001

52. Pereira RI, Draznin B. Inhibition of the phosphatidylinositol 3'kinase signaling pathway leads to decreased insulin-stimulated adiponectin secretion from 3T3-L1 adipocytes. Metabolism. (2005) 54:1636-43. doi: 10.1016/j.metabol.2005.07.002

53. Blumer RM, van Roomen CP, Meijer AJ, Houben-Weerts JH, Sauerwein HP, Dubbelhuis PF. Regulation of adiponectin secretion by insulin and amino acids in 3T3-L1 adipocytes. Metabolism. (2008) 57:165562. doi: 10.1016/j.metabol.2008.07.020

54. Fasshauer M, Klein J, Neumann S, Eszlinger M, Paschke R. Hormonal regulation of adiponectin gene expression in 3T3-L1 adipocytes. Biochem Biophys Res Commun. (2002) 290:1084-9. doi: 10.1006/bbrc.2001.6307

55. Petty RG. Prolactin and antipsychotic medications: mechanism of action. Schizophrenia Res. (1999) 35(Suppl):S6773. doi: 10.1016/S0920-9964(98)00158-3

56. Li J, Rice MS, Huang T, Hankinson SE, Clevenger CV, Hu FB, et al. Circulating prolactin concentrations and risk of type 2 diabetes in US women. Diabetologia. (2018) 61:2549-60. doi: 10.1007/s00125-018-4733-9

57. Ben-Jonathan N, Hugo ER, Brandebourg TD, LaPensee CR. Focus on prolactin as a metabolic hormone. Trends Endocrinol Metab. (2006) 17:1106. doi: 10.1016/j.tem.2006.02.005

58. Yamauchi T, Iwabu M, Okada-Iwabu M, Kadowaki T. Adiponectin receptors: a review of their structure, function and how they work. Best Pract Res Clin Endocrinol Metab. (2014) 28:15-23. doi: 10.1016/j.beem.2013.09.003

59. Yamauchi T, Kamon J, Minokoshi Y, Ito Y, Waki H, Uchida S, et al. Adiponectin stimulates glucose utilization and fatty-acid oxidation by activating AMP-activated protein kinase. Nat Med. (2002) 8:128895. doi: $10.1038 / \mathrm{nm} 788$

60. Kola B, Boscaro M, Rutter GA, Grossman AB, Korbonits M. Expanding role of AMPK in endocrinology. Trends Endocrinol Metab. (2006) 17:20515. doi: 10.1016/j.tem.2006.05.006
61. Viollet B, Foretz M, Guigas B, Horman S, Dentin R, Bertrand L, et al. Activation of AMP-activated protein kinase in the liver: a new strategy for the management of metabolic hepatic disorders. J Physiol. (2006) 574(Pt 1):41-53. doi: 10.1113/jphysiol.2006.108506

62. Aroda V, Ciaraldi TP, Chang SA, Dahan MH, Chang RJ, Henry RR. Circulating and cellular adiponectin in polycystic ovary syndrome: relationship to glucose tolerance and insulin action. Fertil Steril. (2008) 89:1200-8. doi: 10.1016/j.fertnstert.2007.04.046

63. Glintborg D, Frystyk J, Hojlund K, Andersen KK, Henriksen JE, Hermann AP, et al. Total and high molecular weight (HMW) adiponectin levels and measures of glucose and lipid metabolism following pioglitazone treatment in a randomized placebo-controlled study in polycystic ovary syndrome. Clin Endocrinol. (2008) 68:165-74. doi: 10.1111/j.1365-2265.2007.03015.x

64. Fruhbeck G, Catalan V, Rodriguez A, Ramirez B, Becerril S, Salvador $\mathrm{J}$, et al. Involvement of the leptin-adiponectin axis in inflammation and oxidative stress in the metabolic syndrome. Sci Rep. (2017) 7:6619. doi: 10.1038/s41598-017-06997-0

65. Waki H, Yamauchi T, Kamon J, Ito Y, Uchida S, Kita S, et al. Impaired multimerization of human adiponectin mutants associated with diabetes. Molecular structure and multimer formation of adiponectin. J Biol Chem. (2003) 278:40352-63. doi: 10.1074/jbc.M300365200

66. Seino Y, Hirose H, Saito I, Itoh H. High molecular weight multimer form of adiponectin as a useful marker to evaluate insulin resistance and metabolic syndrome in Japanese men. Metabolism. (2007) 56:14939. doi: 10.1016/j.metabol.2007.06.015

67. Seino Y, Hirose H, Saito I, Itoh H. High-molecular-weight adiponectin is a predictor of progression to metabolic syndrome: a population-based 6-year follow-up study in Japanese men. Metabolism. (2009) 58:35560. doi: 10.1016/j.metabol.2008.10.008

68. Lara-Castro C, Luo N, Wallace P, Klein RL, Garvey WT. Adiponectin multimeric complexes and the metabolic syndrome trait cluster. Diabetes. (2006) 55:249-59. doi: 10.2337/diabetes.55.01.06.db05-1105

69. Ren J. Leptin and hyperleptinemia - from friend to foe for cardiovascular function. J Endocrinol. (2004) 181:1-10. doi: 10.1677/joe.0.1810001

70. Lu ML, Wang TN, Lin TY, Shao WC, Chang SH, Chou JY, et al. Differential effects of olanzapine and clozapine on plasma levels of adipocytokines and total ghrelin. Prog Neuropsychopharmacol Biol Psychiatry. (2015) 58:4750. doi: 10.1016/j.pnpbp.2014.12.001

71. Horska K, Ruda-Kucerova J, Babinska Z, Karpisek M, Demlova R, Opatrilova $\mathrm{R}$, et al. Olanzapine-depot administration induces time-dependent changes in adipose tissue endocrine function in rats. Psychoneuroendocrinology. (2016) 73:177-85. doi: 10.1016/j.psyneuen.2016.07.218

72. Ryo M, Nakamura T, Kihara S, Kumada M, Shibazaki S, Takahashi M, et al. Adiponectin as a biomarker of the metabolic syndrome. Circ J. (2004) 68:975-81. doi: 10.1253/circj.68.975

73. Lopez-Jaramillo P, Gomez-Arbelaez D, Lopez-Lopez J, Lopez-Lopez C, Martinez-Ortega J, Gomez-Rodriguez A, et al. The role of leptin/adiponectin ratio in metabolic syndrome and diabetes. Horm Mol Biol Clin Investig. (2014) 18:37-45. doi: 10.1515/hmbci-2013-0053

74. Franks PW, Brage S, Luan J, Ekelund U, Rahman M, Farooqi IS, et al. Leptin predicts a worsening of the features of the metabolic syndrome independently of obesity. Obes Res. (2005) 13:1476-84. doi: 10.1038/oby.2005.178

75. Finucane FM, Luan J, Wareham NJ, Sharp SJ, O’Rahilly S, Balkau $\mathrm{B}$, et al. Correlation of the leptin:adiponectin ratio with measures of insulin resistance in non-diabetic individuals. Diabetologia. (2009) 52:23459. doi: 10.1007/s00125-009-1508-3

76. Vedal TSJ, Steen NE, Birkeland KI, Dieset I, Reponen EJ, Laskemoen JF, et al. Adipokine levels are associated with insulin resistance in antipsychotics users independently of BMI. Psychoneuroendocrinology. (2019) 103:8795. doi: 10.1016/j.psyneuen.2019.01.001

77. Fruhbeck G, Catalan V, Rodriguez A, Gomez-Ambrosi J. Adiponectinleptin ratio: a promising index to estimate adipose tissue dysfunction. Relation with obesity-associated cardiometabolic risk. Adipocyte. (2018) 7:57-62. doi: 10.1080/21623945.2017.1402151

78. Fruhbeck G, Catalan V, Rodriguez A, Ramirez B, Becerril S, Salvador J, et al. Adiponectin-leptin ratio is a functional biomarker of adipose tissue inflammation. Nutrients. (2019) 11:454. doi: 10.3390/nu11020454 
79. Larsen MA, Isaksen VT, Moen OS, Wilsgaard L, Remijn M, Paulssen EJ, et al. Leptin to adiponectin ratio - a surrogate biomarker for early detection of metabolic disturbances in obesity. Nutr Metab Cardiovasc Dis. (2018) 28:1114-21. doi: 10.1016/j.numecd.2018.06.020

80. Kojima M, Hosoda H, Date Y, Nakazato M, Matsuo H, Kangawa K. Ghrelin is a growth-hormone-releasing acylated peptide from stomach. Nature. (1999) 402:656-60. doi: 10.1038/45230

81. De Vriese C, Delporte C. Ghrelin: a new peptide regulating growth hormone release and food intake. Int J Biochem Cell Biol. (2008) 40:14204. doi: 10.1016/j.biocel.2007.04.020

82. Rasineni K, Kubik JL, Knight KL, Hall L, Casey CA, Kharbanda KK. Ghrelin regulates adipose tissue metabolism: role in hepatic steatosis. Chem Biol Interact. (2020) 322:109059. doi: 10.1016/j.cbi.2020.109059

83. Muller TD, Nogueiras R, Andermann ML, Andrews ZB, Anker SD, Argente J, et al. Ghrelin. Mol Metab. (2015) 4:437-60. doi: 10.1016/j.molmet.2015.03.005

84. Zhang Q, Deng C, Huang XF. The role of ghrelin signalling in secondgeneration antipsychotic-induced weight gain. Psychoneuroendocrinology. (2013) 38:2423-38. doi: 10.1016/j.psyneuen.2013.07.010

85. Wittekind DA, Kluge M. Ghrelin in psychiatric disorders - a review. Psychoneuroendocrinology. (2015) 52:17694. doi: 10.1016/j.psyneuen.2014.11.013

86. Theisen FM, Gebhardt S, Haberhausen M, Heinzel-Gutenbrunner M, Wehmeier PM, Krieg JC, et al. Clozapine-induced weight gain: a study in monozygotic twins and same-sex sib pairs. Psychiatr Genet. (2005) 15:2859. doi: 10.1097/00041444-200512000-00011

87. Malan-Muller S, Kilian S, van den Heuvel LL, Bardien S, Asmal L, Warnich $\mathrm{L}$, et al. A systematic review of genetic variants associated with metabolic syndrome in patients with schizophrenia. Schizophrenia Res. (2016) 170:117. doi: 10.1016/j.schres.2015.11.011

88. Yang L, Chen J, Liu D, Yu S, Cong E, Li Y, et al. Association between SREBF2 gene polymorphisms and metabolic syndrome in clozapine-treated patients with schizophrenia. Prog Neuropsychopharmacol Biol Psychiatry. (2015) 56:136-41. doi: 10.1016/j.pnpbp.2014.08.015

89. Li N, Cao T, Wu X, Tang M, Xiang D, Cai H. Progress in genetic polymorphisms related to lipid disturbances induced by atypical antipsychotic drugs. Front Pharmacol. (2019) 10:1669. doi: 10.3389/fphar.2019.01669

90. Gohlke JM, Dhurandhar EJ, Correll CU, Morrato EH, Newcomer JW, Remington $\mathrm{G}$, et al. Recent advances in understanding and mitigating adipogenic and metabolic effects of antipsychotic drugs. Front Psychiatry. (2012) 3:62. doi: 10.3389/fpsyt.2012.00062

91. Fernandez-Egea E, Bernardo M, Donner T, Conget I, Parellada E, Justicia A, et al. Metabolic profile of antipsychotic-naive individuals with non-affective psychosis. Br J Psychiatry. (2009) 194:434-8. doi: 10.1192/bjp.bp.108.052605

92. Spelman LM, Walsh PI, Sharifi N, Collins P, Thakore JH. Impaired glucose tolerance in first-episode drug-naive patients with schizophrenia. Diabet Med. (2007) 24:481-5. doi: 10.1111/j.1464-5491.2007.02092.x

93. Ryan MC, Collins $\mathrm{P}$, Thakore JH. Impaired fasting glucose tolerance in firstepisode, drug-naive patients with schizophrenia. Am J Psychiatry. (2003) 160:284-9. doi: 10.1176/appi.ajp.160.2.284

94. Petruzzelli MG, Marzulli L, Giannico OV, Furente F, Margari M, Matera E, et al. Glucose metabolism, thyroid function, and prolactin level in adolescent patients with first episode of schizophrenia and affective disorders. Front Psychiatry. (2020) 11:775. doi: 10.3389/fpsyt.2020.00775

95. Thakore JH, Mann JN, Vlahos I, Martin A, Reznek R. Increased visceral fat distribution in drug-naive and drug-free patients with schizophrenia. Int J Obes Relat Metab Disord. (2002) 26:137-41. doi: 10.1038/sj.ijo.0801840

96. Bartoli F, Lax A, Crocamo C, Clerici M, Carra G. Plasma adiponectin levels in schizophrenia and role of second-generation antipsychotics: a meta-analysis. Psychoneuroendocrinology. (2015) 56:179-89. doi: 10.1016/j.psyneuen.2015.03.012

97. Bak M, Fransen A, Janssen J, van Os J, Drukker M. Almost all antipsychotics result in weight gain: a meta-analysis. PLoS ONE. (2014) 9:e94112. doi: 10.1371/journal.pone.0094112

98. Newcomer JW. Antipsychotic medications: metabolic and cardiovascular risk. J Clin Psychiatry. (2007) 68(Suppl. 4):8-13. doi: 10.4088/JCP.0307e07
99. Tay YH, Lee J. The relationship between serum adiponectin levels, cardiometabolic indices and metabolic syndrome in schizophrenia. Asian J Psychiatry. (2019) 43:1-6. doi: 10.1016/j.ajp.2019.04.006

100. Hanssens L, van Winkel R, Wampers M, Van Eyck D, Scheen A, Reginster JY, et al. A cross-sectional evaluation of adiponectin plasma levels in patients with schizophrenia and schizoaffective disorder. Schizophrenia Res. (2008) 106:308-14. doi: 10.1016/j.schres.2008.09.008

101. Sarvari AK, Vereb Z, Uray IP, Fesus L, Balajthy Z. Atypical antipsychotics induce both proinflammatory and adipogenic gene expression in human adipocytes in vitro. Biochem Biophys Res Commun. (2014) 450:13839. doi: 10.1016/j.bbrc.2014.07.005

102. von Wilmsdorff M, Bouvier ML, Henning U, Schmitt A, Schneider-Axmann T, Gaebel W. The sex-dependent impact of chronic clozapine and haloperidol treatment on characteristics of the metabolic syndrome in a rat model. Pharmacopsychiatry. (2013) 46:1-9. doi: 10.1055/s-0032-1321907

103. Perez-Iglesias R, Vazquez-Barquero JL, Amado JA, Berja A, GarciaUnzueta MT, Pelayo-Teran JM, et al. Effect of antipsychotics on peptides involved in energy balance in drug-naive psychotic patients after 1 year of treatment. J Clin Psychopharmacol. (2008) 28:28995. doi: 10.1097/JCP.0b013e318172b8e6

104. Raposo NR, Ferreira AS, Gattaz WF. Body mass index increase, serum leptin, adiponectin, neuropeptide $\mathrm{Y}$ and lipid levels during treatment with olanzapine and haloperidol. Pharmacopsychiatry. (2011) 44:16972. doi: 10.1055/s-0031-1280793

105. Hu Y, Kutscher E, Davies GE. Berberine inhibits SREBP-1-related clozapine and risperidone induced adipogenesis in 3T3-L1 cells. Phytother Res. (2010) 24:1831-8. doi: 10.1002/ptr.3204

106. Secher A, Husum H, Holst B, Egerod KL, Mellerup E. Risperidone treatment increases CB1 receptor binding in rat brain. Neuroendocrinology. (2010) 91:155-68. doi: 10.1159/000245220

107. Wampers M, Hanssens L, van Winkel R, Heald A, Collette J, Peuskens J, et al. Differential effects of olanzapine and risperidone on plasma adiponectin levels over time: results from a 3-month prospective open-label study. Eur Neuropsychopharmacol. (2012) 22:17-26. doi: 10.1016/j.euroneuro.2011.03.010

108. Sugai T, Suzuki Y, Fukui N, Ono S, Watanabe J, Tsuneyama N, et al. Dysregulation of adipocytokines related to second-generation antipsychotics in normal fasting glucose patients with schizophrenia. J Clin Psychopharmacol. (2012) 32:390-3. doi: 10.1097/JCP.0b013e3182524393

109. Richards AA, Hickman IJ, Wang AY, Jones AL, Newell F, Mowry BJ, et al. Olanzapine treatment is associated with reduced high molecular weight adiponectin in serum: a potential mechanism for olanzapine-induced insulin resistance in patients with schizophrenia. J Clin Psychopharmacol. (2006) 26:232-7. doi: 10.1097/01.jcp.0000218404.64619.52

110. Cooper GD, Pickavance LC, Wilding JP, Halford JC, Goudie AJ. A parametric analysis of olanzapine-induced weight gain in female rats. Psychopharmacology. (2005) 181:80-9. doi: 10.1007/s00213-005-2224-4

111. Cooper GD, Pickavance LC, Wilding JP, Harrold JA, Halford JC, Goudie AJ. Effects of olanzapine in male rats: enhanced adiposity in the absence of hyperphagia, weight gain or metabolic abnormalities. J Psychopharmacol. (2007) 21:405-13. doi: 10.1177/0269881106069637

112. Minet-Ringuet J, Even PC, Lacroix M, Tome D, de Beaurepaire R. A model for antipsychotic-induced obesity in the male rat. Psychopharmacology. (2006) 187:447-54. doi: 10.1007/s00213-006-0433-0

113. Baptista T, Parada M, Hernandez L. Long term administration of some antipsychotic drugs increases body weight and feeding in rats. Are D2 dopamine receptors involved? Pharmacol Biochem Behav. (1987) 27:399405. doi: 10.1016/0091-3057(87)90340-6

114. Baptista T, Araujo de Baptista E, Ying Kin NM, Beaulieu S, Walker $\mathrm{D}$, Joober $\mathrm{R}$, et al. Comparative effects of the antipsychotics sulpiride or risperidone in rats. I: bodyweight, food intake, body composition, hormones and glucose tolerance. Brain Res. (2002) 957:144-51. doi: 10.1016/S0006-8993(02)03616-8

115. von Wilmsdorff M, Bouvier ML, Henning U, Schmitt A, Gaebel W. The impact of antipsychotic drugs on food intake and body weight and on leptin levels in blood and hypothalamic ob-r leptin receptor expression in wistar rats. Clinics. (2010) 65:885-94. doi: 10.1590/\$1807-59322010000900012 
116. Hahn MK, Wolever TM, Arenovich T, Teo C, Giacca A, Powell V, et al. Acute effects of single-dose olanzapine on metabolic, endocrine, and inflammatory markers in healthy controls. J Clin Psychopharmacol. (2013) 33:740-6. doi: 10.1097/JCP.0b013e31829e8333

117. Vidarsdottir S, Vlug P, Roelfsema F, Frolich M, Pijl H. Orally disintegrating and oral standard olanzapine tablets similarly elevate the homeostasis model assessment of insulin resistance index and plasma triglyceride levels in 12 healthy men: a randomized crossover study. J Clin Psychiatry. (2010) 71:1205-11. doi: 10.4088/JCP.08m04654yel

118. Hosojima H, Togo T, Odawara T, Hasegawa K, Miura S, Kato Y, et al. Early effects of olanzapine on serum levels of ghrelin, adiponectin and leptin in patients with schizophrenia. J Psychopharmacol. (2006) 20:759. doi: 10.1177/0269881105056647

119. Sporn AL, Bobb AJ, Gogtay N, Stevens H, Greenstein DK, Clasen LS, et al. Hormonal correlates of clozapine-induced weight gain in psychotic children: an exploratory study. J Am Acad Child Adolesc Psychiatry. (2005) 44:925-33. doi: 10.1097/01.chi.0000170552.15798.dd

120. Baba LI, Kolcsar M, Kun IZ, Ulakcsai Z, Bagamery F, Szoko E, et al. Effects of cariprazine, aripiprazole, and olanzapine on mouse fibroblast culture: changes in adiponectin contents in supernatants, triglyceride accumulation, and peroxisome proliferator-activated receptorgamma expression. Medicina. (2019) 55:160. doi: 10.3390/medicina550 50160

121. Sarsenbayeva A, Marques-Santos CM, Thombare K, Di Nunzio G, Almby $\mathrm{KE}$, Lundqvist $\mathrm{M}$, et al. Effects of second-generation antipsychotics on human subcutaneous adipose tissue metabolism. Psychoneuroendocrinology. (2019) 110:104445. doi: 10.1016/j.psyneuen.2019.104445

122. Gao L, Zhang X, Jiang Z, Li H. Effects on social functioning and metabolism in the patients with first-episode schizophrenia: aipiprazole vs risperidone. Int J Clin Exp Med. (2020) 13::2888-94.

123. Wang LJ, Ree SC, Huang YS, Hsiao CC, Chen CK. Adjunctive effects of aripiprazole on metabolic profiles: comparison of patients treated with olanzapine to patients treated with other atypical antipsychotic drugs. Prog Neuropsychopharmacol Biol Psychiatry. (2013) 40:260-6. doi: 10.1016/j.pnpbp.2012.10.010

124. Castellani LN, Costa-Dookhan KA, McIntyre WB, Wright DC, Flowers SA, Hahn MK, et al. Preclinical and clinical sex differences in antipsychotic-induced metabolic disturbances: a narrative review of adiposity and glucose metabolism. J Psychiatr Brain Sci. (2019) 4:e190013. doi: $10.20900 /$ jpbs.20190013

125. Peake PW, Kriketos AD, Campbell LV, Shen Y, Charlesworth JA. The metabolism of isoforms of human adiponectin: studies in human subjects and in experimental animals. Eur J Endocrinol. (2005) 153:40917. doi: 10.1530/eje.1.01978

126. Nishizawa H, Shimomura H, Kishida K, Maeda N, Kuriyama $\mathrm{H}$, Nagaretani $\mathrm{H}$, et al. Androgens decrease plasma adiponectin, an insulin-sensitizing adipocyte-derived protein. Diabetes. (2002) 51:2734-41. doi: 10.2337/diabetes.51.9.2734

127. Saltevo J, Kautiainen H, Vanhala M. Gender differences in adiponectin and low-grade inflammation among individuals with normal glucose tolerance, prediabetes, and type 2 diabetes. Gend Med. (2009) 6:46370. doi: 10.1016/j.genm.2009.09.006

128. Matsuda Y, Tanioka T, Yoshioka T, Nagano T, Hiroi T, Yoshikawa $\mathrm{K}$, et al. Gender differences in association of plasma adiponectin with obesity reflect resultant insulin resistance in non-diabetic Japanese patients with schizophrenia. Psychiatry Clin Neurosci. (2005) 59:26673. doi: 10.1111/j.1440-1819.2005.01370.x

129. Mente A, Razak F, Blankenberg S, Vuksan V, Davis AD, Miller R, et al. Ethnic variation in adiponectin and leptin levels and their association with adiposity and insulin resistance. Diabetes Care. (2010) 33:162934. doi: 10.2337/dc09-1392

130. Khoo CM, Sairazi S, Taslim S, Gardner D, Wu Y, Lee J, et al Ethnicity modifies the relationships of insulin resistance, inflammation, and adiponectin with obesity in a multiethnic Asian population. Diabetes Care. (2011) 34:1120-6. doi: 10.2337/dc10-2097

131. Kizer JR, Arnold AM, Strotmeyer ES, Ives DG, Cushman M, Ding J, et al. Change in circulating adiponectin in advanced old age: determinants and impact on physical function and mortality. The Cardiovascular Health Study All Stars Study. J Gerontol Ser A Biol Sci Med Scie. (2010) 65:120814. doi: $10.1093 /$ gerona/glq122

132. Kizer JR, Barzilay JI, Kuller LH, Gottdiener JS. Adiponectin and risk of coronary heart disease in older men and women. J Clin Endocrinol Metab. (2008) 93:3357-64. doi: 10.1210/jc.2008-0640

133. Kizer JR, Benkeser D, Arnold AM, Djousse L, Zieman SJ, Mukamal KJ, et al. Total and high-molecular-weight adiponectin and risk of coronary heart disease and ischemic stroke in older adults. J Clin Endocrinol Metab. (2013) 98:255-63. doi: 10.1210/jc.2012-2103

134. Srisawasdi P, Vanwong N, Hongkaew Y, Puangpetch A, Vanavanan S, Intachak B, et al. Impact of risperidone on leptin and insulin in children and adolescents with autistic spectrum disorders. Clin Biochem. (2017) 50:678-85. doi: 10.1016/j.clinbiochem.2017.02.003

Conflict of Interest: The authors declare that the research was conducted in the absence of any commercial or financial relationships that could be construed as a potential conflict of interest.

Copyright (C) 2021 Chen, Goh, Chen and Lu. This is an open-access article distributed under the terms of the Creative Commons Attribution License (CC BY). The use, distribution or reproduction in other forums is permitted, provided the original author(s) and the copyright owner(s) are credited and that the original publication in this journal is cited, in accordance with accepted academic practice. No use, distribution or reproduction is permitted which does not comply with these terms. 